\title{
Research on the Library Users' Information Retrieval Behaviour: From a Bibliometric Perspective
}

\author{
Wencheng Su1, Yinglin Sun ${ }^{2 *}$ \\ ${ }^{1}$ Institute of Science and Technology Information in Jiangsu University, Zhenjiang, China \\ ${ }^{2}$ Management School in Jiangsu University, Zhenjiang, China \\ Email:694789822@qq.com, ${ }^{*}$ bao5ye@ujs.edu.cn
}

How to cite this paper: Su, W.C. and Sun, Y.L. (2020) Research on the Library Users' Information Retrieval Behaviour: From a Bibliometric Perspective. Open Access Library Journal, 7: e6460.

https://doi.org/10.4236/oalib.1106460

Received: May 25, 2020

Accepted: July 20, 2020

Published: July 23, 2020

Copyright $\odot 2020$ by author(s) and Open Access Library Inc.

This work is licensed under the Creative Commons Attribution International License (CC BY 4.0).

http://creativecommons.org/licenses/by/4.0/

(c) (i) Open Access

\begin{abstract}
This paper presents an international literature review on the hot topic of library users' information retrieval behaviour in recent years. Through the usage of bibliometric content analysis and social network analysis methods, the paper finishes the work of data cleaning and integration, referring to the quantitative analysis of results produced by CiteSpace, a literature citation visualization analysis software, to summarize the main branches and focuses of this area. The researchers find that academia primarily focuses on the field of mechanisms and model research of users' information retrieval behaviour, users' information demands research, information literacy cultivation, and information retrieval system design and optimization, among other significant findings. Through the panoramic analysis and interpretation of research on international library users' information retrieval behaviour provided by this article, conducted from a bibliometrics perspective, the researchers establish a clear overview and an effective reference of the research hotspots in this area.
\end{abstract}

\section{Subject Areas}

Information Retrieval Behaviour, Library User Study

\section{Keywords}

Visualization Analysis, Library Information Retrieval Behaviour, Literature Review, Bibliometric Content Analysis

\section{Introduction}

With the backdrop of the network era and the emergence of an ever-changing variety of brand-new techniques, the area of library users' information retrieval 
behaviour research has reached a new peak in transformation and development. A series of literature reviews have been produced in the field of health information and medical information search. For example, the information needs and information retrieval behaviors of primary care physicians and nurses were assessed [1]; researches of information searching behavior during the process of hospital nurses decision-making were evaluated in different reviews [2] [3]; the study of retrieval and utilization of information sources in critical patients has also received considerable attention [4]. In addition, there have been a number of summarized research achievements in the fields of information retrieval behavior of graduate students [5], public network health information retrieval behavior analysis [6], and systematic musical information retrieval behavior analysis [7]. However, there are few researches in the area of information retrieval behavior focusing on library user groups.

To sum up, the traditional research methodologies in terms of information retrieval study field used by past researchers are collapsing under the pressure from various challenges due to the considerably rapid development of technology, producing an urgent need for the clarification of the developing branches and hotspots in this area from a fresh perspective. Meanwhile, it is necessary to review international literature to identify the innovative concepts and advanced technologies within this topic of research. Accordingly, this article digs into the current situation in library users' information behaviour research from the angle of bibliometrics. The aim of this study is to gain insight into library users' information needs, motivations, and retrieval behavior mechanisms for seeking information in the physical or digital library environment and to develop a better understanding of what information resources to present to library user group through analyzing studies that assessed the information searching behaviour of users in all types of libraries.

\section{Methodology and Bibliometrics of Related Research Fields}

\subsection{Searching Strategy}

This study chooses Science Citation Index Expanded (SCI-EXPANDED), Social Sciences Citation Index (SSCI), and Conference Proceedings Citation Index-Science (CPCI-S) in the Web of Science Core Collection database as retrieval sources. The associated search strategy is TS $=$ (library or librar $\left.{ }^{\star}\right)$ AND (Information need ${ }^{*}$ OR Information retrieval ${ }^{*}$ OR Information behavio* OR information seek ${ }^{\star}$ OR Information management ${ }^{\star}$ OR Information source ${ }^{\star}$ OR information resource $)^{*}$, and Time Span is from 2000.1.1 to 2019.12.31. The search process has archived the bibliographic information of 9924 articles; after sorting by relevance and manual literature data cleaning, the study eventually resulted in 5785 related literature items.

${ }^{1}$ This paper used "library or librar" to represent for the singular and plural forms of "library", and used "behavio*" to represent for "behavior" and "behaviour". 


\subsection{Basic Information Analysis of Literature}

As can be seen in Figure 1, the amount of literature on this topic has increased steadily from 2000 to 2019, reaching a peak in 2019, and the average annual number of articles is roughly 289 , meaning that the scholars in this area have remained enthusiastic about the topic and archived the fruitful results.

Generally speaking, the authors in this area who have written highly-cited articles usually come from universities or institutions in developed countries, such as top-ranked author Ina Fourie from the University of Pretoria in South Africa, who is interested in such areas as users' information retrieval systems, personal information management, and online learning, among other topics. Those high yielding authors, as listed in Figure 2, who had high quality research results and fruitful achievements, like Ina Fourie, deserve the concern and attention of the

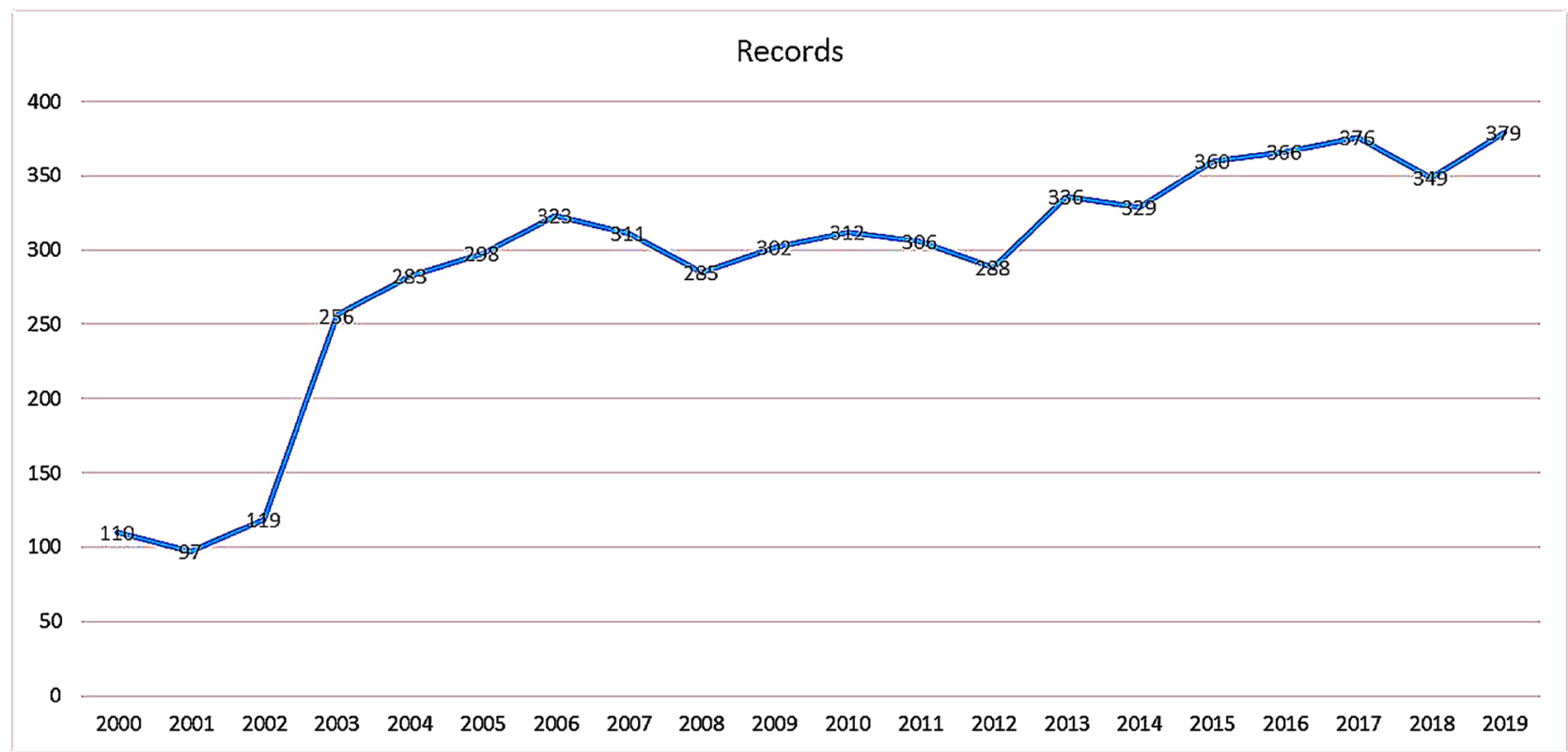

Figure 1. Number of articles published annually.

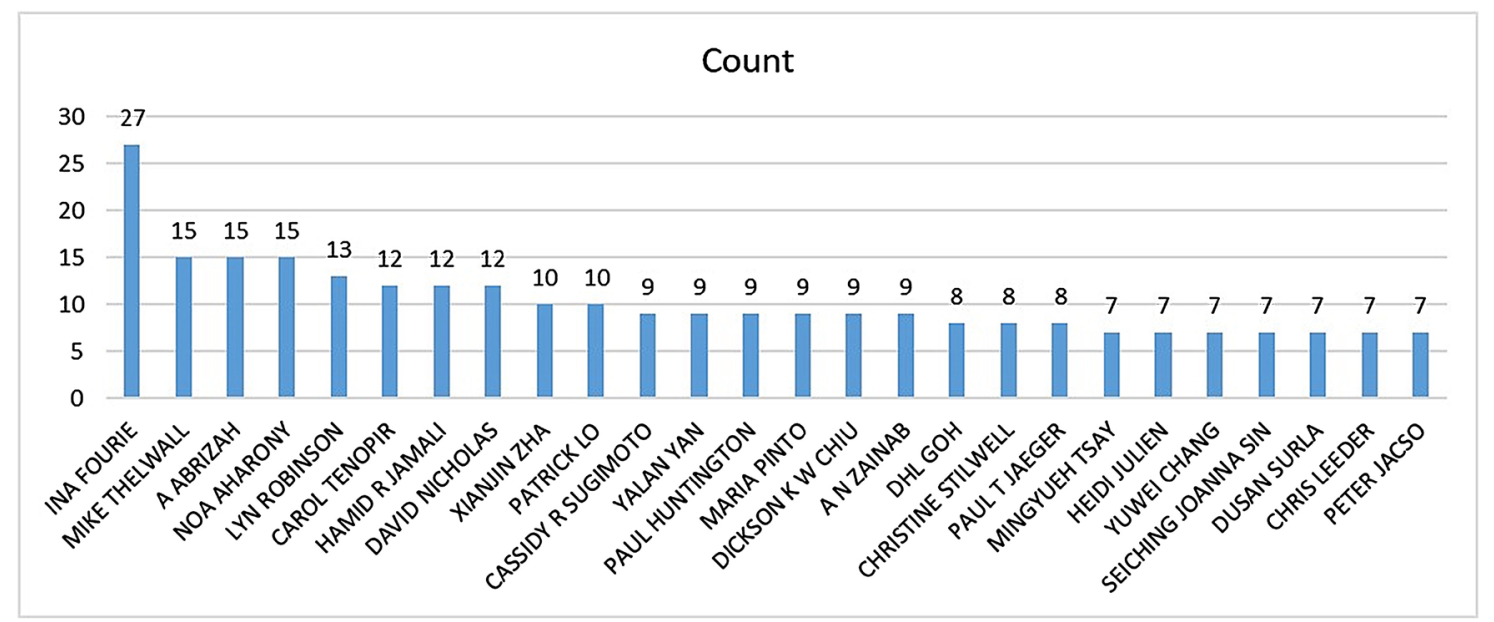

Figure 2. Highly cited authors ranked by number of citations. 
academic community.

As for highly-cited journals (see Figure 3), all belong to the category of the Social Sciences Citation Index, containing series of solid quality articles that could be referenced by researchers. Top-ranked journals like Electric Library or Journal of Academic Librarianship illustrate that the research area of users' information behaviour mainly focuses on information behaviours at the digital and network level.

Figure 4, developed using CiteSpace 5.6.R5 (64 bit), a classic bibliometric and literature social network analyzing software used for visually metrological analysis based on bibliography and citation data achieved from research papers, demonstrates the situation of cooperation and influence of researchers from different disciplines. The colorful annual ring images with various sizes represent the number of articles published by authors of different disciplines, while the links represent cooperation patterns among those authors. It is obvious that the overwhelming majority of authors are researchers from the field of information science \& library science. The second majority is computer science, which also plays a significant role in this area due to the strong relationship between information behaviour research and digital network research. Meanwhile, Figure 4 reveals that interdisciplinary research has become a reality, including several disciplines, such as psychology, medicine (nursing), management (operation research and management), biology (biochemical and molecular biology, mathematical and computational biology, biotechnology) and engineering, among others.

\subsection{Analysis of Literature Citation}

Quantitative research conducted by using of CiteSpace and Ucinet social network visualization software can distinguish the potential research branches and hotspots that could not be discovered apparently by intuitional observations. The study receives Figure 5 after importing literature bibliography data into

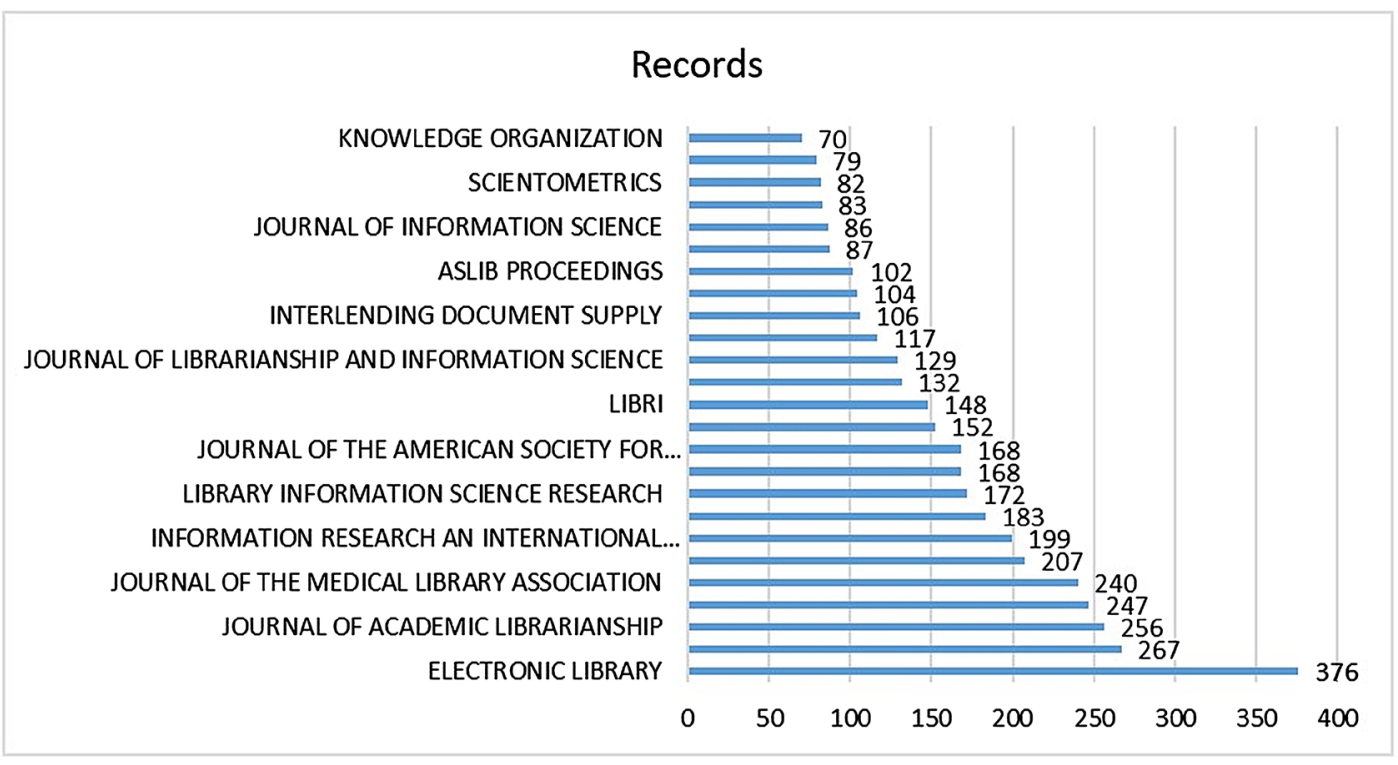

Figure 3. Highly cited journals ranked by number of citations. 


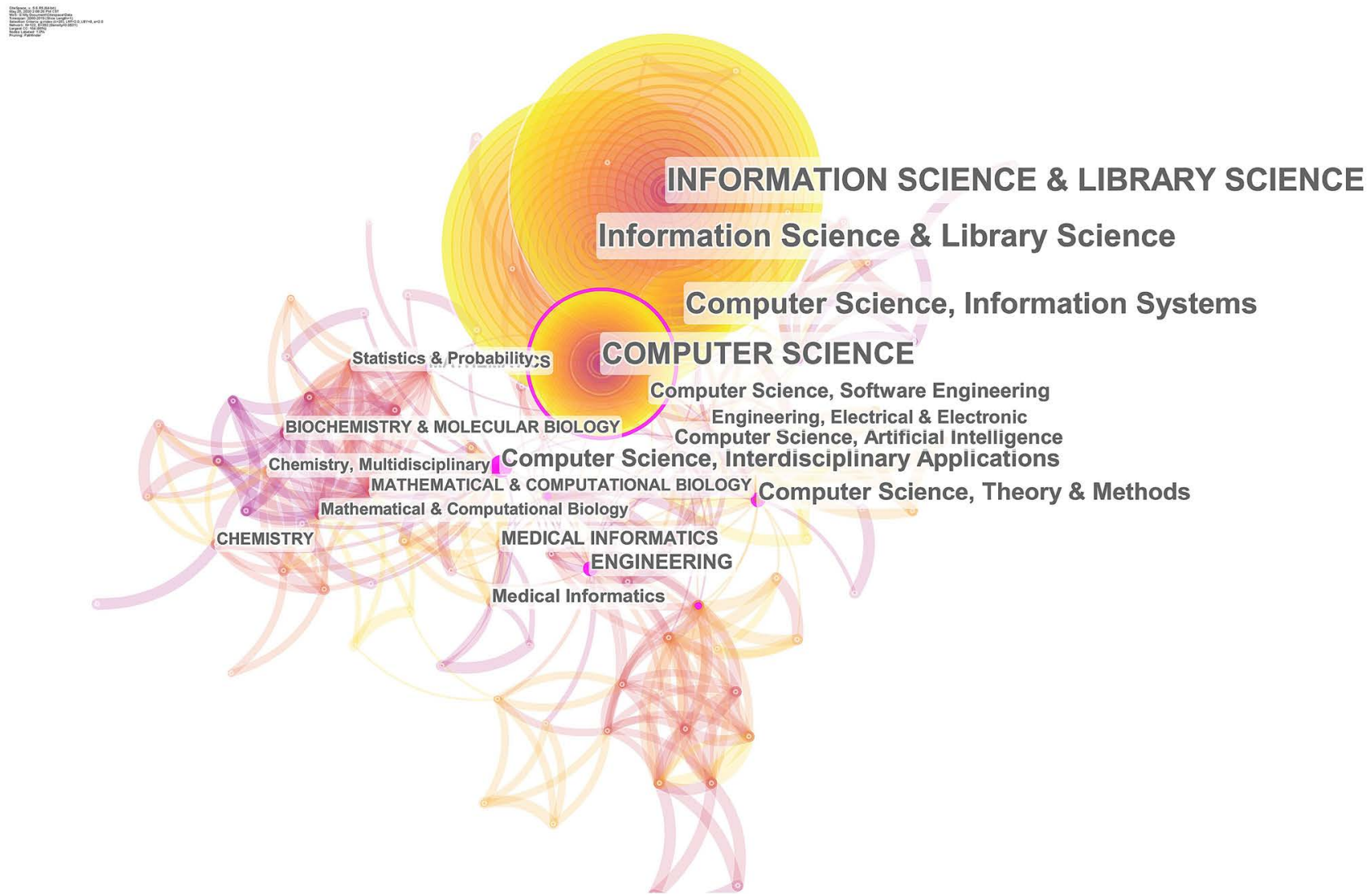

Figure 4. The disciplines within library users' information retrieval behaviour research.

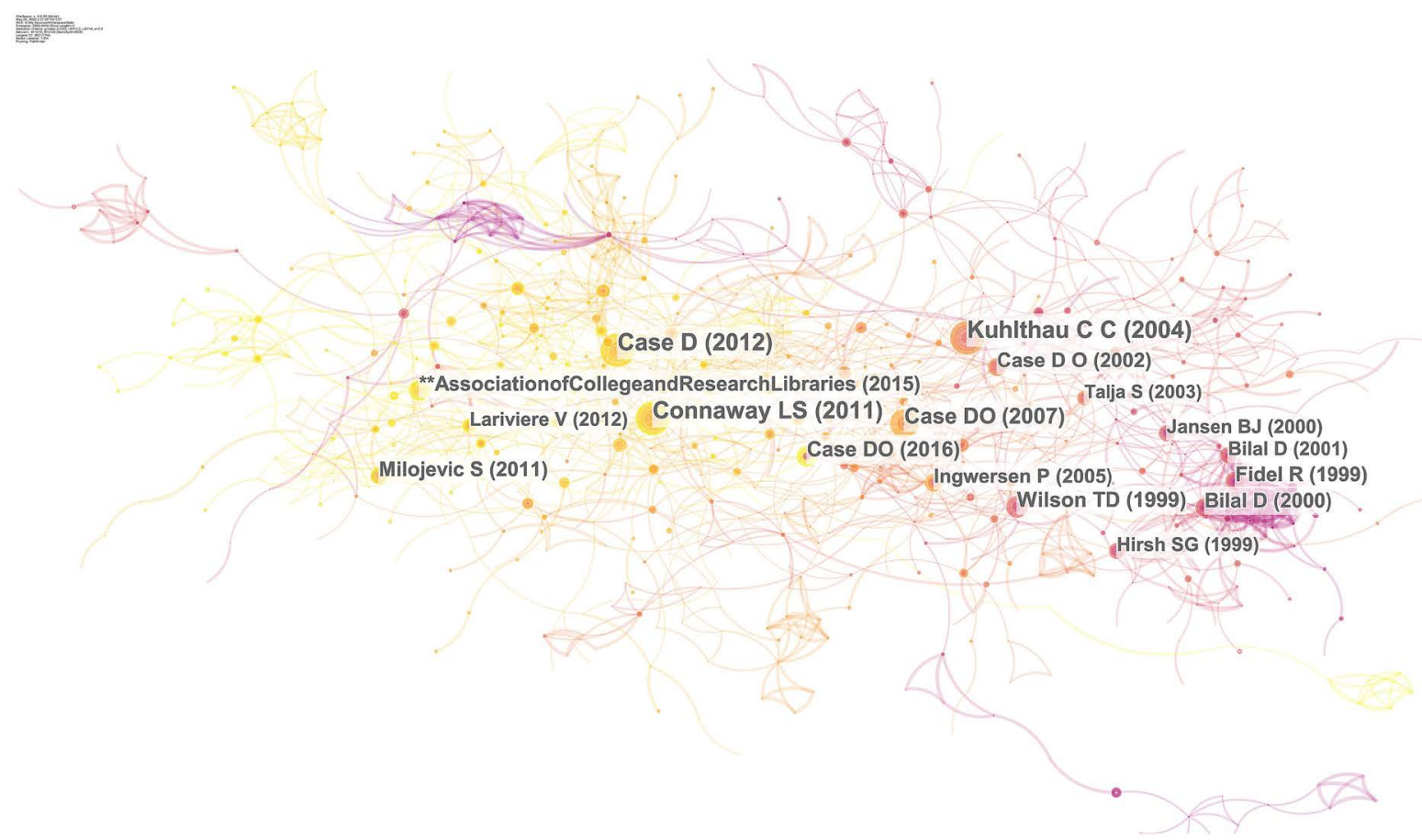

Figure 5. Visualization of co-cited literature. 


\section{CiteSpace.}

Most researchers could not continue their study without the basis of former researchers' works, refer to the study of information seeking behaviour fundamental theory, retrieval information behaviour models and information retrieval system design. The articles of scholars in early stage such as Thomas D. Wilson (Models in information behaviour research) and Carol C. Kuhlthau (Inside the search process. Information seeking from the user's perspective), who put forward the theory of information retrieval behaviour models, are cited repeatedly by followers. Reading literatures written by these authors could be beneficial to newcomers' research works.

With the help of CiteSpace's Burst Finding Algorithm, it is extremely simple to identify burst references among 5785 articles, and these burst references act as turning points and have incomparable value in the developing process of information behaviour analysis. Table 1 shows the location of burst references.

Table 1. Top 24 references with the strongest citation bursts.

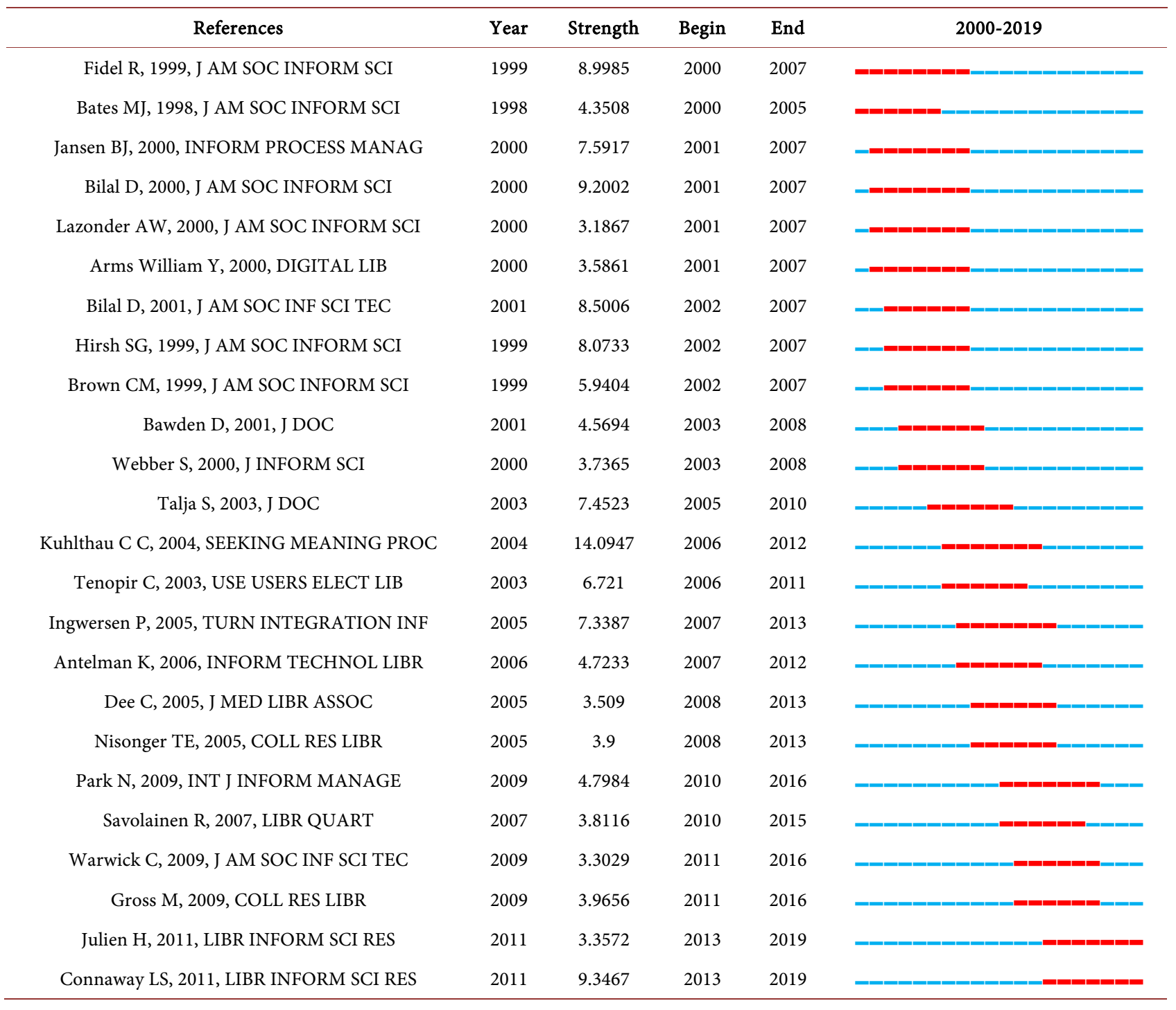


The themes of burst literatures include the research of human information behaviour [8], information behaviour modeling [9], library information retrieval services design [10], and everyday-life information seeking behaviour research [11]. In addition, information needs analysis [12], children's information retrieval behaviour research [13], information retrieval behaviour research in the digital environment [14], academic information retrieval behaviour research [15], and digital information resources retrieval behaviour research by using commercial search engines all received the attention from scholars [16].

\subsection{Analysis of Keywords Co-Occurrence}

The keywords co-occurrence phenomenon could generally be used in the analysis of research themes in certain academic fields. The various combinations between different keywords in the same contextual environment could usually reflect the focuses of research work in an article. Figure 6 illustrates the keywords co-occurrence in the area of library users' information behaviour research, drawn by CiteSpace, Ucinet, and NetDraw software. The image was developed by referencing the keywords co-occurrence calculating results provided by $\mathrm{Ci}$ teSpace and manually concluding the high-frequency co-occurrence keywords into the clusters 1 to 7 , shown below in the circles with dotted lines and sequence number.

According to Figure 6, Cluster 1 is the core keyword cluster that highlights, which represents for a) information literacy education research, is highly correlated to other keywords and one of the hottest spots in this field; b) Investigation

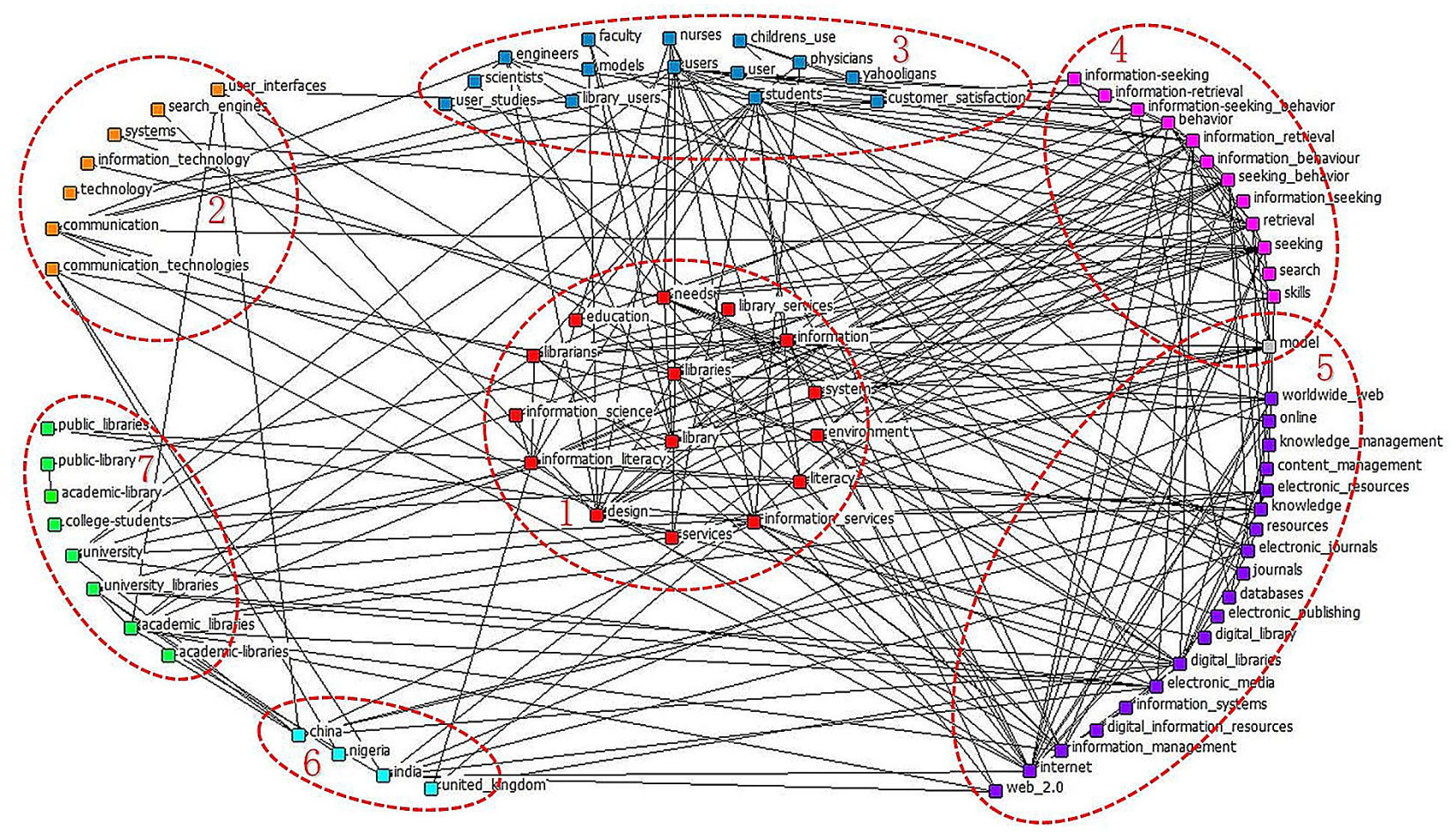

Figure 6. High frequency keywords co-occurrence social network clusters. 
of different types of users' information demands is crucial part of this research field; c) All kinds of library information services.

Cluster 2 is a library information system and information technology related keywords group. Cluster 3 is a sematic group that contains a large number of keywords which refer to research participants in the area of library information behaviour research. Cluster 4 is the keywords group consisting of users' information retrieval research and information seeking behaviour. Cluster 5 is worth noting that digital library model building and knowledge management models are still the focus of this research branch. Cluster 6 groups keywords relating to geographic information. Cluster 7 is the group of keywords relating to university and public libraries, in which researchers focus on topics in university library users' information retrieval behaviour within the network environment, use of university library digital information resources, information literacy of college library users, and information services in public libraries.

\subsection{High Frequency Keywords Co-Occurrence Social Network Clusters}

Using the analysis results in chapter 2.4, this part of the article discusses the core hotspots in the area of library users' information behaviour research in the last 3 years (2017-2019). By analyzing the keywords co-occurrence time line view image in Figure 7, produced using CiteSpace, some development trends could be revealed immediately. The following hotspots have become the focus of scholarly research: concluding information behaviour analysis based on bibliographic records, institutional repositories, college student information seeking, library anxiety, health information demands, public libraries and children's libraries, information systems usability, multi-source documental data analysis, and academic

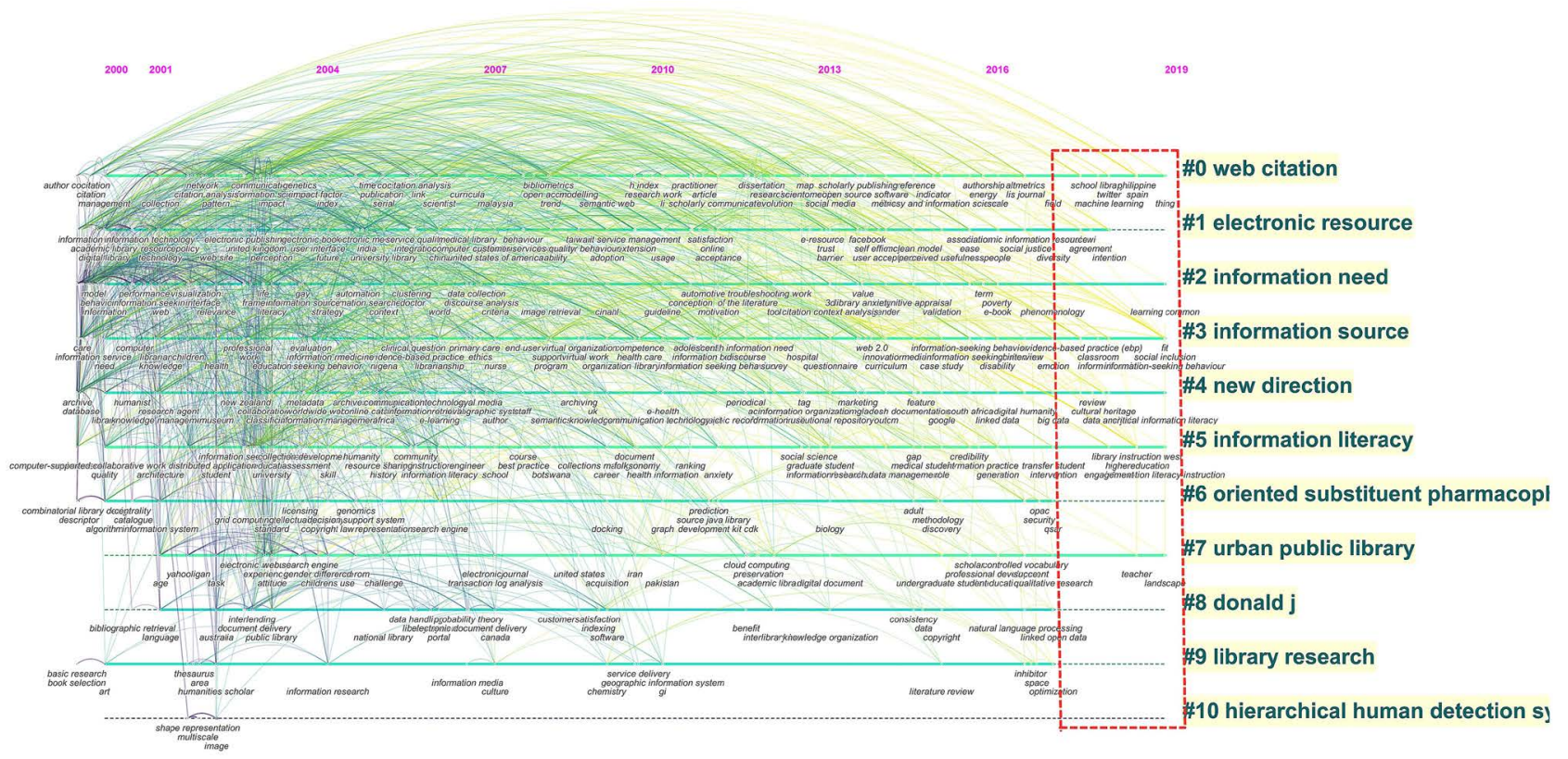

Figure 7. Time line view of keywords co-occurrence. 
plagiarism detection.

\section{Summary of Research Focuses and Branches}

\subsection{Research on Users' Information Retrieval Behaviour Mechanisms and Patterns}

1) Models of user information retrieval behaviour. Users' information retrieval behaviour models have indispensable and fundamental functions in the research of users' information behavioural mechanisms, pattern analysis, and prediction, since behaviour models usually illustrate the entire process of the generation mechanism of users' information demands, retrieval links, and results presented by conceptual graph models. One of the classic models in this area is the human information seeking behaviour model designed by Thomas D. Wilson, which regards users' information behaviour as its core and also refers to communications, the transfer and access of information. Significantly, this model places a high emphasis on user demands, and the effective correlation between satisfaction toward retrieval results and initial information demands. Carol C. Kuhlthau's user information search process model divides the process into six phases, including initiation, selection, exploration formulation, collection and presentation, also integrating the uncertainty in information seeking, the interaction of thoughts, emotions, and actions into the model [17].

In recent years, with the rapid development of information and digital network technology, the classic models of information retrieval have been challenged as new models endlessly emerge. Natalya Godbold discussed the "sequence" shortcoming of traditional information retrieval models, taking models given by Thomas D. Wilson and Brenda Dervin as cases, and proposes the "multi-directionality" concept of information behaviour models [18]. Mohammed Nasser Al-Suqri designed an information behaviour model aligned with the actual information environment of developing countries through an empirical analysis of the information behaviour of social scientists in middle eastern universities with the support provided by NVivo qualitative software [19]. Furthermore, there is another study discussing the applicability of the Information Search Processing (ISP) model in the background of virtual learning, imitating Carol C. Kuhlthau's (1989) sequence research, which proved that the ISP model can be independent of the physical library environment and the users' computer operating experience has no effect on the patterns of thoughts, feelings, and actions in the model [20].

Other models have emerged, such as a four-part model of reference service that emphasizes public library users' information demands and service interactions [21]; a user information search model that integrates the elements of information seeking and communication [22]; and a model of user information search behaviour organization [23], which provides a theoretical basis for exploring the characteristics and mechanism of users' information retrieval behaviour.

2) User information organizational behaviour patterns. Some scholars try 
to explain the characteristics of user information seeking behaviour from the perspective of information organization. One article collected the information of users' folksonomy usage from the website CiteULike and analyzed the users' information retrieval preferences and behaviour patterns, finding that the emerging frequency of user tag categories and individual tags obeyed a power law distribution [24]. The users' information retrieval behaviour, as the basic activity in information organization, always has the purpose of achieving their information tasks, and information demand is the core concept of information retrieval behaviour theory [25]. Frances Hultgren took Swedish university students information user as an example, analyzing the information retrieval behaviour features of individuals and illustrating the social attributes of barriers to young users' information obtaining behaviour, finally providing suggestions for information resources retrieval optimization at the level of organization [26]. Su Kan Lin tried to explain the reasons for the similarities and differences between Chinese and Australian library information associations by comparing and summarizing the development purposes, organization, and member structures [27]. Meanwhile, there is a research that expounded the transformation and developing trends of knowledge organizations (KO) in the pre-internet and post-internet environments, claiming that new content areas, metadata, cataloging, and classification problems continually influence the directions of knowledge development. At the microscopic level, the organization development and the information services of the libraries of American Indian culture has become increasingly attractive in the academia [28].

3) Users information retrieval motivation and satisfaction research. Research on the evaluation of the information retrieval results could reveal users' satisfaction or motivation by means of qualitative or quantitative methods, and focus on the entire user behaviour information retrieval process, including the associated psychological behaviour theory according to the literature reviews. Reijo Savolainen argued that emotions are motivators that stimulating a user's information retrieval behaviour [29]. The initiation, expansion, limitation, termination, or avoidance of information seeking could be affected by positive or negative feelings such as happiness, anxiety, and fear. Another study conducted a questionnaire investigation by using the Information Seeking Self-Efficacy Scale, finding that age, education level, experiences, emotional condition, and social feedback influences self-efficacy of information seeking behaviour [30]. The results of empirical research by Paulus Insap Santosa et al. showed that intrinsic and situational motivations are the basis for user information involvement [31]. Intrinsic motivations could more effectively urge user involvement than situational motivation. However, situational motivation affects a user's satisfaction more strongly than intrinsic motivation. In an article by Angela Weiler, the relationship between users' information seeking behaviour, motivation, critical thinking, and learning theory is discussed, and the author claims that only a small number of modern students are accustomed to gaining knowledge 
from books [32]. Another study asserted that traditional library services and resources still play a critical role in users' satisfaction and impact factors of information resources retrieval. According to a study of the information resource acquisition of university faculty in Pakistan, books, communication with colleagues, and journal articles are main sources of information retrieval [33]. Most interviewees said that they would like to use library information resources over other sources, reporting that they were highly satisfied with the information services provided by their libraries.

4) Users borrowing behaviour research. There is a considerable abundance of research methods and techniques which have been applied in the area of user borrowing behaviour research. Radio Frequency Identification (RFID) has been used in a study to track user information resource usage and search paths to gain insight into the participants' information seeking patterns [34]. Another study showed how Geographical Information System (GIS) can be used in a medium-sized public library in southern Florida [35]. In the study, more than 100 entering paths of users were analyzed, and the frequently-used paths were marked. The study found that library resources, equipment layout strategies, and location of services could be adjusted to increase the efficiency of users' research and information seeking. Additionally, Lisa M. Given marked and analyzed users' in-library behaviour patterns by combining Visual Traffic Sweeps (VTS) and GIS technology [36]. The visualization results of the study could be used in optimizing library management policies and spatial planning decisions.

The emergence of electronic books in academia has highlighted the research of users' e-book borrowing behaviour. One researcher interviewed 76 undergraduate student users and investigated their attitudes and reading habits with regards to print and electronic books, finding that users generally hold positive attitudes and enthusiasm toward e-books [37]. At the same time, electronic resource utilization in libraries is quite low, and e-books are most commonly utilized for leisure reading. Furthermore, students tend to search for academic e-book resources using a web browser, and especially like marking and managing their e-books resources on the electronic users [38].

5) Online user information retrieval behaviour. Online information retrieval research has shown its crucial value in the area of information behaviour study in the modern internet environment. A comparative study asked college students to search selected topics in literature on Google and library search tools. The author suggests that, according to his findings, the user interface and user experience of library search tools could be improved by referencing commercial search engines [39]. Similarly, another study of Google's search engine found that physicists and astronomers prefer using Google to access the information resources they need [40]. This study also found that the number of papers retrieved via the Google Scholar searching website has gradually increased, as has independent Google usage by scholars. D.J. Clark et al.'s research showed that current information professionals and publishers comprehend the influence of 
user behaviours in the virtual environment by analyzing their online information retrieval behaviour data [41].

\subsection{Research of Users' Multi-Requirements and Behaviour in the Information Retrieval Process}

1) School and the academic library user's information retrieval behaviour. The amount of research on the information demands and seeking behaviour of university and academic users represents a major proportion of the research of user information resources retrieval. Jannica Heinström et al. explored students' learning-related information searching behaviour personality, including intellectual curiosity, conscientiousness and negative emotionality, and found that personality tremendously influences the completion of experimental design learning tasks [42]. Meanwhile, in contrast with the traditional concept that student users use internet search engines for retrieving resources, a study found that accessing information recommendation services on library websites and those provided by academic librarians could be more efficient in terms of building personal information systems [43]. An investigation on digital information resources retrieval and usage of students of art and design subjects showed that comfort with the library, as well as a student's information needs will affect their source of inspiration [44]. Additionally, information retrieval behaviour on the internet and social networks will arouse students' design inspiration. Another similar study by Kyung Sun Kim et al. suggested that librarians and educational workers could archive their information literacy program using social media and video sharing websites [45]. In addition, research subjects such as the analysis of information retrieval behaviour characteristics and the needs of agriculture scientists [46], the study of historians' information retrieval behaviour conceptual model construction [47], the design of actual information demands and information services of humanities scholars [48], the analysis of mathematics researchers' information behaviour characteristics online [49], the mining of aerospace and astrophysics scientists' information needs and behaviour features [50], and the construction of information retrieval behaviour models of information specialists are extensively studied by international scholars [51].

The research of children and young users' information retrieval behaviour continues to be an important topic in this area. A study indicated that the stages of kindergartens, primary, and secondary schools (K-12 American plan) are significant periods for children in forming their health information literacy and good information behaviour habits [52]. An effective model of instruction for children would have critical value to the schools, school libraries, curriculum design, educational technology development, and education policy formulation [53]. Thus, child-friendly information searching system design, search engine design, and digital library development are emerging as hotspots in this field.

2) Research of information retrieval behaviour of health care workers. The widespread extension of electronic health information and electronic in- 
formation systems within the health care industry has brought about the healthcare information explosion era. Meanwhile, the area of medical information retrieval behaviour characteristic analysis has achieved a string of high quality researches. Nurses as a group were found to have a low level of information literacy according to the results of research conducted in Singapore [54] and Evidence Based Practice (EBP) medical systems [55]. Peter Stokes optimized nurses' information retrieval models and information literacy course design for nurses with a scale investigation he designed [56]. Sandra L. De Groote et al. argued that librarians should assist scholars in locating and utilizing the library's academic information resources and provide information searching tools through a comparative study on usage frequency of health sciences faculty of specialized online databases and Google search engine [57].

On the other side, health care information research is gradually becoming the focus in the field. One study analyzed public library users' health information retrieval behaviour and evaluated public library health information services according to the feedback provided by the users [58]. For the purpose of dealing with information poverty problems, another study discussed the possibility of interdisciplinary collaboration among scholars in daily life information search field in terms of electronic information resources design [59]. Additionally, branches such as public health information library service navigation service design [60], research on librarians' deficiency in health care information resources and professional knowledge [61], the analysis of libraries' strategy of public health education and online health information promotion [62], and research on health information promotion in universities have been highly valued by academia [63].

3) Everyday life information retrieval. Everyday life information retrieval, as one of the most vital types of information retrieval behaviour, is a significant branch of the area of information retrieval behaviour. Lisa O'Connor tried to investigate the information behaviour of retired investors and found that gender, economic status, and educational level influence information behaviour [64]. These findings were duplicated by a study of international students' information behaviour in academic libraries [65]. An investigation of participants' naturalistic daily life online information retrieval behaviour conducted by Pia Borlund et al. [66] confirmed the theory of three types of information needs given by Peter Ingwersen, who identified the verificative information problems (VIN), the conscious topical information problems (CIN), and the muddled topical information problems (MIN) [67]. An in-depth interview comparing a housewife's everyday life information sharing behaviour in an informal online and off-line environment illustrated how the internet can significantly promote a housewife's information demands, as well as their high dependence on the internet [68]. Some scholars dedicated themselves to the study of Asian immigrants' daily information retrieval behaviour [69]. At the same time, in relation to domestic violence, researchers suggested that public libraries should provide supportive in- 
formation and support for victims in a private and secure way [70].

4) Other information retrieval behaviour patterns. In addition to the research of information retrieval needs and information behaviour types mentioned above, the study of the library's role in the satisfaction of the law faculties' information demands and guidance of their information retrieval behaviour [71], the library users receiving approaches and patterns of public government information [72], the library's guidance in government information retrieval [73], the influencing factors of distance learning user information retrieval behaviour [74], analysis of the digital library users search log [75], the library's guidance and help seeking for distance users [76], and even housekeeping staff's information retrieval behaviour characteristics are generally involved with a practical significance to people in every walk of life [77].

\subsection{Information Literacy Research}

1) Health information retrieval and monitoring of health information literacy. The scholars in the field also highlight the users' health information retrieval behaviour research. One article focused on the health literacy of the library user and their perception of their own health information behaviour [78]. By using a short-circuit test survey, the author identified a correlation between library users' health literacy, gender, education level, and demographic characteristics. According to the findings of another academic Course/Learning Management Systems (CMS) research, librarians are increasingly providing information through the CMS platform in recent years, which has been shown to be a perfect tool for promoting health information literacy [79]. In addition, the continued poor condition of American citizens' health information has aroused the attention of scholars, and it was argued that the responsibility for providing public health information search services should be the in the hands of public libraries [80]. Health information literacy is lacking on both the side of the librarians and the side of the users, which could be the main obstacle in the process of popularizing public health literacy. Meanwhile, some British researchers have taken note of the number of users who have treated public libraries as their authoritative source for health information, second only to hospitals [81]. However, patients cannot in fact always acquire all of the health information they need. For the purpose of proving what they found and analyzing of the advantages of public libraries offering health information online, one study examined the cooperative plan between the British governmental health authorities, health advocacy organizations, and 10 public libraries [82].

2) Cultivation of information literacy. Cultivation of information literacy will always be the one of hotspots in the area of information behaviour research. A study of instructors and doctoral students conducted by Nina Exner showed that the current information literacy educating process is far from meeting the actual teaching and academic needs [83]. Through the analysis of the ADDIE model (analysis, design, development, implementation, and evaluation), Kim- 
berly Mullins found that user demand for library-assisted teaching and researching is gradually increasing with an emphasis on integration of information literacy within discipline instruction [84]. However, most librarians have not accepted any kind of formal instructional design training. Instruction in how to identify, retrieve, analyze, and use the information they need could be the core of information literacy education for undergraduates due to the significance of undergraduates' personal information collecting, managing, and retrieval [85]. Arthur Taylor and Heather A. Dalal discussed the critical implications of information literacy education given by commercial search engines and websites to the students, and presents source evaluation criteria of reliability, validity, accuracy, authority, timeliness and point of views or bias [86]. An information literacy research given by Maria do Carmo Avamilano Alvarez et al. illustrated the gatekeeper role of librarians and their function in enhancing student users' learning ability [87]. In addition, a study highlighted the function of librarians by analyzing the similarities between the information retrieval process and fiction reading, and fostered a strong foundation of user information literacy development [88]. Finally, facing the current condition of the suffocated information literacy education and the lack of motivation, another study argued that librarians should implement institutional cooperation with other stakeholders to ensure the development of information literacy promotion policy [89].

\subsection{Library Information Retrieval Systems}

Some intensive studies of user information retrieval systems have been conducted. The study of system reliability ranking should be the first question to be tackled. In additional to the diversity of retrieval results, the six dimensions of text statistics, popularity, freshness, locality and availability, content properties and user background were identified as the standards of library information retrieval system evaluation [90]. Robert Marijan and Robert Leskovar described the effectiveness of information retrieval components and open source alternatives in the Integrated Library System (ILS) [91]. Furthermore, they discussed the alternative function of ILS compared to more traditional information retrieval systems. Virtual reference services are also becoming a new branch in this area. A study looked at the Chinese website Baiduzhidao, finding that libraries should seek to emulate the primary functions of Social Questions and Answers (SQA) websites' virtual information services [92]. D. A. Amit Kumar and Sukumar Mandal reviewed the development of library integrated management and retrieval systems under cloud calculating technology, which resulted in proposing the design of Service Oriented Architecture (SOA), Open Library Environment Project (OLE), and Integrated Library Systems for Discovery Interface (ILS-DI) [93]. More recently, a literature review of multi-lingual digital library information retrieval revealed that most researchers still focus their study around retrieval system design, regardless of the patrons' actual information needs [94]. Information retrieval behaviour and expectations have not received 
enough attention.

\section{Conclusions}

This article summarizes the branches and the hot topics in the area of library users' information retrieval behaviour by analyzing the characteristics of the collected literature from the perspective of information science bibliometrics methods. The research finds that most majority of scholars mainly focused on the study of users' information retrieval behaviour mechanisms and patterns, users' multi-requirements and behaviour of the retrieval of information resources, cultivation of users' information literacy, and library information retrieval systems.

On the whole, researchers in this area have contributed series of intensive and solid works to the academia in which major critical research problems have been analyzed meticulously and a range of brilliant achievement have been gained in the environment of internet. Particularly, a range of practical academic results were produced in the area of user information retrieval behaviour models building and validation, users information retrieval motivation and satisfaction, Users' borrowing behaviour, investigation of information needs of different types of users, medical and health caring information retrieval behavioural pattern, even cultivation of information literacy of users.

However, in contrast to the tremendously thriving situation of digital network resources retrieval study area, the research area of libraries' physical resources (books, journals, disks on shelves) searching still has remained a lackluster condition in the academia. It is clear that research is imbalanced, in that it is excessively concentrated on virtual/online information search behaviour, rather than physical/offline information retrieval, which should arouse scholars' attention. As a significant branch of users' information resource retrieval behaviour research, physical information resources searching study should be seen equally as a core topic in this area. Even more importantly, the enormous difference could be occurred in terms of behavioural patterns, habits, characteristics, mechanism, impact factors between the study of virtual resources and physical resources retrieval, due to the diversity of information resources searching environment, media resources and retrieval tools. Therefore, the connotation of users' information retrieval behaviour research could be positively enriched through enhancing the emphasis level of scholars on physical resources searching behaviour of library users, meanwhile, which also could play a significantly practical role in guidance of users' in-library information retrieval behaviour research work.

It is obvious to find that, through the conclusion of literature review, further study of physical information resources retrieval behaviour of library users with the help of emerging digital technics will be a breakthrough in the future development of this field. A study attempted to exploit how to use the Visual Traffic Sweeps (VTS) technology to visualize moving path and behaviour of library users, and an optimization of library spatial planning could be proposed from the 
perspective of physical information resources using behaviour of users, which preliminary reflects the vital function that VTS technic could has in the study of in-library information behaviour [36]. Jingfeng Xia creatively mapped the status of books using frequency on shelves by the GIS technology software, and made the on-shelves information searching behaviour considerably explicit in a visualizing way [95].

On this basis, drawing on research methods and means across disciplines, such as behavioural science theories, eye movement analysis in reading research, and even the biographical signal feedback technologies, might be able to indicates a possible research direction for future researchers and provides a new perspective and methodology for the booming development of this field.

\section{Acknowledgements}

We gratefully acknowledge the support from China's Ministry of Education Humanities and Social Sciences Research Program (Grant NO.: 20YJC870008, hosted by Wencheng Su); and the support from Jiangsu University Library Program (Grant NO.: TSG2019K02, hosted by Wencheng Su); and the support from Postgraduate Research \& Practice Innovation Program of Jiangsu Province (Grant NO.: KYCX19_1565, hosted by Yinglin Sun).

\section{Conflicts of Interest}

The authors declare no conflicts of interest regarding the publication of this paper.

\section{References}

[1] Clarke, M.A., Belden, J.L., Koopman, R.J., et al. (2013) Information Needs and Information-Seeking Behaviour Analysis of Primary Care Physicians and Nurses: A Literature Review. Health Information \& Libraries Journal, 30, 178-190. https://doi.org/10.1111/hir.12036

[2] Alving, B.E., Christensen, J.B. and Thryso, L. (2018) Hospital Nurses' Information Retrieval Behaviours in Relation to Evidence Based Nursing: A Literature Review. Health Information and Libraries Journal, 35, 3-23. https://doi.org/10.1111/hir.12204

[3] Cranley, L., Doran, D.M., Tourangeau, A.E., et al. (2009) Nurses' Uncertainty in Decision-Making: A Literature Review. Worldviews on Evidence-Based Nursing, 6, 3-15. https://doi.org/10.1111/j.1741-6787.2008.00138.x

[4] Corcoran, T.B., Haigh, F., Seabrook, A., et al. (2009) The Quality of Internet-Sourced Information for Patients with Chronic Pain Is Poor. Clinical Journal of Pain, 25, 617-623. https://doi.org/10.1097/AJP.0b013e3181a5b5d5

[5] Catalano, A. (2013) Patterns of Graduate Students Information Seeking Behavior: A Meta-Synthesis of the Literature. The Journal of Documentation, 69, 243-274. https://doi.org/10.1108/00220411311300066

[6] Boot, C.R.L. and Meijman, F.J. (2010) The Public and the Internet: Multifaceted Drives for Seeking Health Information. Health Informatics Journal, 16, 145-156. https://doi.org/10.1177/1460458210364786 
[7] Lavranos, C., Kostagiolas, P., Korfiatis, N. and Papadatos, J. (2016) Information Seeking for Musical Creativity: A Systematic Literature Review. Journal of the Association for Information Science \& Technology, 67, 2105-2117.

[8] Wilson, T.D. (2000) Human Information Behavior. Informing Science: The International Journal of an Emerging Transdiscipline, 3, 49-56.

[9] Alzahrani, A., Mahmud, I., Ramayah, T., et al. (2017) Modelling Digital Library Success Using the DeLone and McLean Information System Success Model. Journal of Librarianship and Information Science, 51, 329-354. https://doi.org/10.1177/0961000617726123

[10] Kuhlthau, C.C. (1991) Inside the Search Process: Information Seeking from the User's Perspective. Journal of the American Society for Information Science, 42, 361-371. https://doi.org/10.1002/(SICI)1097-4571(199106)42:5<361::AID-ASI6>3.0.CO;2-\#

[11] Kuhlthau, C.C. (2004) Seeking Meaning: A Process Approach to Library and Information Services. Portal: Libraries and the Academy, 4, 440-441. https://doi.org/10.1353/pla.2004.0054

[12] Savolainen, R. (2013) Looking for Information: A Survey of Research on Information Seeking, Needs, and Behavior. Library \& Information Science Research, 35, 251-252. https://doi.org/10.1016/j.lisr.2013.05.002

[13] Bilal, D. (2001) Children's Use of the Yahooligans! Web Search Engine: II. Cognitive and Physical Behaviors on Research Tasks. Journal of the American Society for Information Science and Technology, 52, 118-136. https://doi.org/10.1002/1097-4571(2000)9999:9999<::AID-ASI1038>3.0.CO;2-R

[14] Tenopir, C., King, D.W. and Boyce, P. (2005) Relying on Electronic Journals: Reading Patterns of Astronomers. Journal of the American Society for Information Science and Technology, 56, 786-802. https://doi.org/10.1002/asi.20167

[15] Hemminger, B.M., Lu, D.H., Vaughan, K.T.L. and Adams, S.J. (2007) Information Seeking Behavior of Academic Scientists. Journal of the American Society for Information Science and Technology, 58, 2205-2225. https://doi.org/10.1002/asi.20686

[16] Rowlands, I., Nicholas, D., Williams, P., Huntington, P., Fieldhouse, M., Gunter, B., Withey, R., Jamali, H.R., Dobrowolski, T. and Tenopir, C. (2008) The Google Generation: The Information Behaviour of the Researcher of the Future. Aslib Proceedings: New Information Perspectives, 60, 290-310. https://doi.org/10.1108/00012530810887953

[17] Kuhlthau, C.C. (1999) Accommodating the User's Information Search Process: Challenges for Information Retrieval System Designers. Bulletin of the American Society for Information Science \& Technology, 25, 12-16. https://doi.org/10.1002/bult.115

[18] Godbold, N. (2005) Beyond Information Seeking: Towards a General Model of Information Behaviour. Information Research, 11, 9.

[19] Al-Suqri, M.N. (2011) Information-Seeking Behavior of Social Science Scholars in Developing Countries: A Proposed Model. The International Information \& Library Review, 43, 1-14. https://doi.org/10.1080/10572317.2011.10762875

[20] Byron, S.M. and Young, J.I. (2000) Information Seeking in a Virtual Learning Environment. Research Strategies, 17, 257-267. https://doi.org/10.1016/S0734-3310(01)00055-6

[21] Westbrook, L. (2015) I'm Not a Social Worker: An Information Service Model for Working with Patrons in Crisis. Library Quarterly, 85, 6-25. 
https://doi.org/10.1086/679023

[22] Robson, A. and Robinson, L. (2013) Building on Models of Information Behaviour: Linking Information Seeking and Communication. Journal of Documentation, 69, 169-193. https://doi.org/10.1108/00220411311300039

[23] Joseph, P., Debowski, S. and Goldschmidt, P. (2013) Models of Information Search: A Comparative Analysis. Information Research, 18, 160-183.

[24] Chen, Y.N. and Ke, H.R. (2013) An Analysis of Users' Behaviour Patterns in the Organisation of Information a Case Study of Citeulike. Online Information Review, 37, 638-656. https://doi.org/10.1108/OIR-05-2012-0086

[25] Thellefsen, M., Thellefsen, T.L. and Sørensen, B. (2013) A Pragmatic Semeiotic Perspective on the Concept of Information Need and Its Relevance for Knowledge Organization. Knowledge Organization, 40, 213-224.

https://doi.org/10.5771/0943-7444-2013-4-213

[26] Hultgren, F. (2013) The Stranger's Tale: Information Seeking as an Outsider Activity. Journal of Documentation, 69, 275-294. https://doi.org/10.1108/00220411311300075

[27] Lin, S.K. (2000) A Comparison of Organizational Structures and Member Categories of the Australian Library and Information Association and the Library Association of China. Bulletin of the Library Association of China, 65, 111-124.

[28] Wood, M. (1975) Initial Organization and Staffing Patterns for Indian Library Services: Staffing for Indian Library Services. National Indian Education Association, Minneapolis, 1-17.

[29] Savolainen, R. (2014) Emotions as Motivators for Information Seeking: A Conceptual Analysis. Library \& Information Science Research, 36, 59-65.

https://doi.org/10.1016/j.lisr.2013.10.004

[30] Bronstein, J. (2014) The Role of Perceived Self-Efficacy in the Information Seeking Behavior of Library and Information Science Students. Journal of Academic Librarianship, 40, 101-106. https://doi.org/10.1016/j.acalib.2014.01.010

[31] Santosa, P.I., Wei, K.K. and Chan, H.C. (2005) User Involvement and User Satisfaction with Information-Seeking Activity. European Journal of Information Systems, 14, 361-370. https://doi.org/10.1057/palgrave.ejis.3000545

[32] Weiler, A. (2005) Information-Seeking Behavior in Generation Y Students: Motivation, Critical Thinking, and Learning Theory. The Journal of Academic Librarianship, 31, 46-53. https://doi.org/10.1016/j.acalib.2004.09.009

[33] Rafiq, M. and Ameen, K. (2009) Information Seeking Behavior and User Satisfaction of University Instructors: A Case Study. Library Philosophy and Practice, 240, $1-12$.

[34] Sugie, N. (2013) Application of Radio Frequency Identification Technology to Study Library Users' Information-Seeking Behavior. Library \& Information Science Research, 35, 69-77. https://doi.org/10.1016/j.lisr.2012.06.006

[35] Mandel, L.H. (2010) Toward an Understanding of Library Patron Wayfinding: Observing Patrons' Entry Routes in a Public Library. Library \& Information Science Research, 32, 116-130. https://doi.org/10.1016/j.lisr.2009.12.004

[36] Given, L.M. (2015) Visual Traffic Sweeps (VTS): A Research Method for Mapping User Activities in the Library Space. Library \& Information Science Research, 37, 100-108. https://doi.org/10.1016/j.lisr.2015.02.005

[37] Lin, W.-J. and Yueh, H.-P. (2012) Examining College Students' Reading Behaviors and Needs for Ebook Users. Journal of Library and Information Studies, 10, 
113-142.

[38] Shenton, A.K. (2011) Uniting Information Literacy Promotion and User Development in Schools: Two Forms of Library-Based Intervention. IFLA Journal, 37, 62-68. https://doi.org/10.1177/0340035210396998

[39] Georgas, H. (2014) Google vs. the Library Part II, Student Search Patterns and Behaviors When Using Google and a Federated Search Tool. Portal-Libraries and the Academy, 14, 503-532. https://doi.org/10.1353/pla.2014.0034

[40] Jamali, H.R. and Asadi, S. (2010) Google and the Scholar: The Role of Google in Scientists' Information-Seeking Behaviour. Online Information Review, 34, 282-294. https://doi.org/10.1108/14684521011036990

[41] Clark, D.J., Nicholas, D. and Jamali, H.R. (2014) Evaluating Information Seeking and Use in the Changing Virtual World: The Emerging Role of Google Analytics. Learned Publishing, 27, 185-194. https://doi.org/10.1087/20140304

[42] Heinström, J., Sormunen, E. and Kaunisto-Laine, S. (2014) Spanning Information Behaviour across the Stages of a Learning Task Where Do Personality and Approach to Studying Matter? Journal of Documentation, 70, 1076-1097. https://doi.org/10.1108/JD-02-2014-0041

[43] Chen, Y.H. (2015) Testing the Impact of an Information Literacy Course: Undergraduates' Perceptions and Use of the University Libraries' Web Portal. Library \& Information Science Research, 37, 263-274. https://doi.org/10.1016/j.lisr.2015.04.002

[44] Lo, P. and Chu, W. (2015) Information for Inspiration: Understanding Information-Seeking Behaviour and Library Usage of Students at the Hong Kong Design Institute. Australian Academic \& Research Libraries, 46, 101-120. https://doi.org/10.1080/00048623.2015.1019604

[45] Kim, K.-S., Joanna Sin, S.-C. and Yoo-Lee, E.Y. (2014) Undergraduates' Use of Social Media as Information Sources. College \& Research Libraries, 75, 442-457. https://doi.org/10.5860/crl.75.4.442

[46] Mugwisi, T., Ocholla, D.N. and Mostert, B.J. (2014) An Overview of the Information Needs of Agricultural Researchers and Extension Workers in Zimbabwe. Libri, 64, 85-108. https://doi.org/10.1515/libri-2014-0008

[47] Darby, P. and Clough, P. (2013) Investigating the Information-Seeking Behaviour of Genealogists and Family Historians. Journal of Information Science, 39, 73-84. https://doi.org/10.1177/0165551512469765

[48] Al-Shboul, M.K. and Abrizah, A. (2014) Information Needs: Developing Personas of Humanities Scholars. Journal of Academic Librarianship, 40, 500-509. https://doi.org/10.1016/j.acalib.2014.05.016

[49] Sapa, R., Krakowska, M. and Janiak, M. (2014) Information Seeking Behaviour of Mathematicians: Scientists and Students. Information Research, 19, 1-11.

[50] Du, W.C. and Song, S. (2013) Information Needs Analysis of the Aerospace Discipline. Aslib Proceedings, 65, 376-387. https://doi.org/10.1108/AP-04-2012-0034

[51] Hayes, R.M., Karlics, K. and Schloegl, C. (2013) University Libraries as a Model for the Determination of the Need for Information Specialists in Knowledge Industries? An Exploratory Analysis of the Information Sector in Austria. Information Processing \& Management, 49, 1008-1018. https://doi.org/10.1016/j.ipm.2013.04.001

[52] Diekema, A.R. and Olsen, M.W. (2014) Teacher Personal Information Management (Pim) Practices: Finding, Keeping, and Re-Finding Information. Journal of the As- 
sociation for Information Science and Technology, 65, 2261-2277. https://doi.org/10.1002/asi.23117

[53] Gossen, T. and NüRnberger, A. (2013) Specifics of Information Retrieval for Young Users: A Survey. Information Processing \& Management, 49, 739-756. https://doi.org/10.1016/j.ipm.2012.12.006

[54] Majid, S., Foo, S., Zhang, X., Mokhtar, I.A., Luyt, B., Chang, Y.-K. and Theng, Y.-L. (2013) Nurses' Information Use and Literature Searching Skills for Evidence Based Practices. Malaysian Journal of Library \& Information Science, 18, 67-78.

[55] Farokhzadian, J., Khajouei, R. and Ahmadian, L. (2015) Information Seeking and Retrieval Skills of Nurses: Nurses Readiness for Evidence Based Practice in Hospitals of a Medical University in Iran. International Journal of Medical Informatics, 84, 570-577. https://doi.org/10.1016/j.ijmedinf.2015.03.008

[56] Stokes, P. and Urquhart, C. (2015) Profiling Information Behaviour of Nursing Students: Part 2: Derivation of Profiles. Journal of Documentation, 71, 52-79. https://doi.org/10.1108/JD-07-2013-0091

[57] De Groote, S.L., Shultz, M. and Blecic, D.D. (2014) Information-Seeking Behavior and the Use of Online Resources: A Snapshot of Current Health Sciences Faculty. Journal of the Medical Library Association, 102, 169-176. https://doi.org/10.3163/1536-5050.102.3.006

[58] Yi, Y.J. (2015) Consumer Health Information Behavior in Public Libraries: A Qualitative Study. Library Quarterly, 85, 45-63. https://doi.org/10.1086/679025

[59] Sabelli, M. (2014) Health Care Information for Youth in Vulnerability Contexts: Designing a Website with an Interdisciplinary and Participatory Approach. Information Research, 19, 239-242.

[60] Lê, M.L. (2014) Information Needs of Public Health Students. Health Information and Libraries Journal, 31, 274-292. https://doi.org/10.1111/hir.12082

[61] Oh, S. and Noh, Y. (2013) Online Health Information in South Korean Public Libraries: Developing Evaluation Criteria. Library \& Information Science Research, 35, 78-84. https://doi.org/10.1016/j.lisr.2012.09.001

[62] Gray, K., Elliott, K. and Wale, J. (2013) A Community Education Initiative to Improve Using Online Health Information: Participation and Impact. Informatics for Health \& Social Care, 38, 171-181. https://doi.org/10.3109/17538157.2012.705201

[63] Duhon, L. and Jameson, J. (2013) Health Information Outreach: A Survey of Us Academic Libraries, Highlighting a Midwestern University's Experience. Health Information and Libraries Journal, 30, 121-137. https://doi.org/10.1111/hir.12017

[64] O'Connor, L.G. (2013) The Information Seeking and Use Behaviors of Retired Investors. Journal of Librarianship and Information Science, 45, 3-22. https://doi.org/10.1177/0961000611434761

[65] Joanna Sin, S.-C. (2015) Demographic Differences in International Students' Information Source Uses and Everyday Information Seeking Challenges. Journal of Academic Librarianship, 41, 466-474. https://doi.org/10.1016/j.acalib.2015.04.003

[66] Borlund, P. and Dreier, S. (2014) An Investigation of the Search Behaviour Associated with Ingwersen's Three Types of Information Needs. Information Processing and Management, 50, 493-507. https://doi.org/10.1016/j.ipm.2014.03.001

[67] Davies, R. (1986) Intelligent Information Systems. Ellis Horwood Limited, Chichester, 223.

[68] Yeh, N.-C. (2013) Reflections on Information Field Theory through Research on Housewife Information Behaviors. Journal of Library and Information Science Re- 
search, 7, 123-152.

[69] Khoir, S., Du, J.T. and Koronios, A. (2015) Linking Everyday Information Behaviour and Asian Immigrant Settlement Processes: Towards a Conceptual Framework. Australian Academic \& Research Libraries, 46, 86-100. https://doi.org/10.1080/00048623.2015.1024303

[70] Westbrook, L. and Gonzalez, M.E. (2011) Information Support for Survivors of Intimate Partner Violence: Public Librarianship's Role. Public Library Quarterly, 30, 132-157. https://doi.org/10.1080/01616846.2011.575709

[71] Bhatt, A.A. (2014) Information Needs, Perceptions and Quests of Law Faculty in the Digital Era. Electronic Library, 32, 659-669.

https://doi.org/10.1108/EL-11-2012-0152

[72] Snead, J.T. (2015) National Government Information Library Network. Library Quarterly, 85, 278-294. https://doi.org/10.1086/681611

[73] González, Y.M. and Terra, A.L.S. (2013) Need for, Demand for, and Use of European Union Information. LIBRI, 63, 320-338.

https://doi.org/10.1515/libri-2013-0025

[74] Tury, S., Robinson, L. and Bawden, D. (2015) The Information Seeking Behaviour of Distance Learners: A Case Study of the University of London International Programmes. Journal of Academic Librarianship, 41, 312-321. https://doi.org/10.1016/j.acalib.2015.03.008

[75] Zavalina, O. and Vassilieva, E.V. (2014) Understanding the Information Needs of Large-Scale Digital Library Users Comparative Analysis of User Searching. Library Resources \& Technical Services, 58, 84-99. https://doi.org/10.5860/lrts.58n2.84

[76] Tang, Y.Q. and Tseng, H.W. (2014) Distance Students' Attitude toward Library Help Seeking. Journal of Academic Librarianship, 40, 307-312.

https://doi.org/10.1016/j.acalib.2014.04.008

[77] Mansour, E.A.H. (2015) Information Needs of Local Domestic Workers in the Arab Republic of Egypt. Electronic Library, 33, 643-667. https://doi.org/10.1108/EL-01-2014-0012

[78] Yong, J.Y. (2015) Health Literacy and Health Information Behavior of Florida Public Library Users: A Mixed Methods Study. Journal of Librarianship and Information Science, 47, 17-29. https://doi.org/10.1177/0961000614531159

[79] Lyons, T. and Warlick, S. (2013) Health Sciences Information Literacy in Cms Environments: Learning from Our Peers. Electronic Library, 31, 770-780. https://doi.org/10.1108/EL-06-2012-0063

[80] Hessler, K.E. (2015) Health Literacy and Law: Empowering Libraries to Improve Access to Consumer Health Information and Aca Compliance. The Serials Librarian, 69, 334-346. https://doi.org/10.1080/0361526X.2015.1105767

[81] Kent, P. (2012) Emerging Health Roles in Public Libraries. Managing Information, $19,42-43$.

[82] Manero, E. and Clarke, M. (2007) What Can Public Libraries Bring to Patient Choice? Library + Information Update, 6, 35-37.

[83] Exner, N. (2014) Research Information Literacy: Addressing Original Researchers' Needs. Journal of Academic Librarianship, 40, 460-466. https://doi.org/10.1016/j.acalib.2014.06.006

[84] Mullins, K. (2014) Good Idea: Instructional Design Model for Integrating Information Literacy. Journal of Academic Librarianship, 40, 339-349.

https://doi.org/10.1016/j.acalib.2014.04.012 
[85] Stewart, K.N. and Basic, J. (2014) Information Encountering and Management in Information Literacy Instruction of Undergraduate, Students. International Journal of Information Management, 34, 74-79. https://doi.org/10.1016/j.ijinfomgt.2013.10.007

[86] Taylor, A. and Dalal, H.A. (2014) Information Literacy Standards and the World Wide Web: Results from a Student Survey on Evaluation of Internet Information Sources. Information Research, 19, 1-33.

[87] Alvarez, M.C.A., Franca, I., Cuenca, A.M.B., Bastos, F.I., Ueno, H.M., Barros, C.R. and Guimaraes, M.C.S. (2014) Information Literacy: Perceptions of Brazilian Hiv/Aids Researchers. Health Information and Libraries Journal, 31, 64-74. https://doi.org/10.1111/hir.12047

[88] Ukachi, N.B. (2015) Information Literacy of Students as a Correlate of their Use of Electronic Resources in University Libraries in Nigeria. Electronic Library, 33, 486-501. https://doi.org/10.1108/EL-05-2013-0085

[89] Baro, E.E., Seimode, F.D. and Godfrey, V.Z. (2013) Information Literacy Programmes in University Libraries: A Case Study. LIBRI, 63, 282-294. https://doi.org/10.1515/libri-2013-0023

[90] Behnert, C. and Lewandowski, D. (2015) Ranking Search Results in Library Information Systems-Considering Ranking Approaches Adapted from Web Search Engines. The Journal of Academic Librarianship, 41, 725-735. https://doi.org/10.1016/j.acalib.2015.07.010

[91] Marijan, R. and Leskovar, R. (2015) A Library's Information Retrieval System (in) Effectiveness: Case Study. Library Hi Tech, 33, 369-386. https://doi.org/10.1108/LHT-07-2015-0071

[92] Deng, S.L., Yang, L.N. and Zhang, Y. (2014) Social Q\&As or Library Virtual Reference Service: What Is behind the Choices of Chinese Information Seekers? LIBRI, 64, 327-340. https://doi.org/10.1515/libri-2014-0026

[93] Amit Kumar, D.A. and Mandal, S. (2013) Development of Cloud Computing in Integrated Library Management and Retrieval System. International Journal of Library and Information Science, 5, 394-400.

[94] Vassilakaki, E. and Garoufallou, E. (2013) Multilingual Digital Libraries: A Review of Issues in System-Centered and User-Centered Studies, Information Retrieval and User Behavior. The International Information \& Library Review, 45, 3-19. https://doi.org/10.1080/10572317.2013.10766367

[95] Xia, J.F. (2004) Using GIS to Measure In-Library Book-Use Behavior. Information Technology and Libraries, 23, 184-191. https://doi.org/10.6017/ital.v23i4.9663 